unsuspected phenomena, he must, to survive and to adapt, acquire new personal qualities and assert new ethical standards. And it is in that context that your work is significant...

To bring the action of the Red Cross up to date and assess its possibilities for development in tomorrow's world, such were the reasons which induced the League of Red Cross Societies and the International Committee of the Red Cross to assign to the Henry Dunant Institute the investigation of which the meeting in Basle was the final phase. That, however, was only the first stage. Other meetings will follow which, it is hoped, will make it possible to define both the possibilities and the limits of humanitarian action in a rapidly changing world.

\title{
RED CROSS INFORMATION MEETING
}

In response to a joint invitation from the International Committee of the Red Cross and the League of Red Cross Societies, some twenty experts from different National Red Cross Societies met in Geneva, on 3 November 1972, to hear reports on current Red Cross programmes in Indochina and on those being prepared.

The Red Cross experts considered the various possibilities for increased humanitarian action following a cease-fire in that part of the world, with the agreement of the local authorities and of the Red Cross bodies directly responsible. Pending such a cease-fire, the Red Cross regards it as imperative to reinforce its current programmes so that it may be able to fulfil its traditional tasks on a larger scale. 